\title{
Rural-urban Health Disparities for Cardiovascular Disease in the Republic of Kazakhstan
}

\author{
Gulbarshyn Mukasheva $^{1 *}$ D, Tolkyn Bulegenov $^{2}$ iD, Vladimir Kolyado ${ }^{3}$, Altynai Kazyeva $^{4}$ (D) \\ ${ }^{1}$ Department of Public Health, NCJSC "Semey Medical University," Semey, Kazakhstan; ${ }^{2}$ Department of Hospital and Pediatric \\ Surgery, NCJSC "Semey Medical University," Semey, Kazakhstan; ${ }^{3}$ Department of Public Health and Health, Federal State \\ Budgetary Educational Institution of Higher Education "Altai State Medical University" of the Russian Federation Ministry of \\ Health, Barnaul, Russia; ${ }^{4}$ Department of Cardiology and Interventional Arrhythmology, NCJSC "Semey Medical University," \\ Semey, Kazakhstan
}

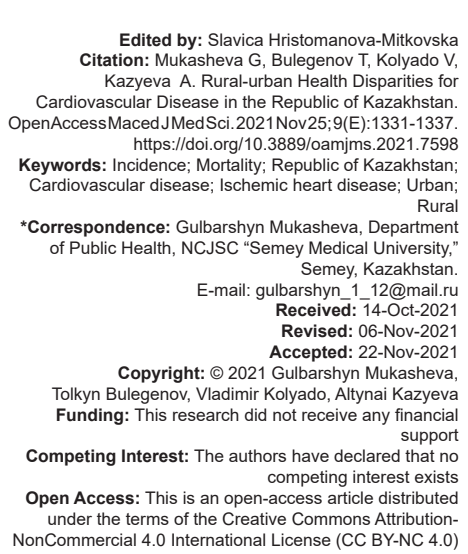

Introduction

Cardiovascular diseases (CVDs) are still the leading cause of mortality in many countries of the world, for no other reason, as many people do not die every year as from CVD [1]. According to the World Health Organization, 17.9 million people died from CVD in 2016 , which is $31 \%$ of all deaths in the world [1], more than 8 million people of this number died from ischemic heart disease (IHD). Kazakhstan ranks first in terms of mortality from CVD among the countries of the European Union, Central and Eastern Europe, and Central Asian regions. According to the World Health Organization (WHO), the standardized mortality rate of the population of the Republic of Kazakhstan due to CVD is 2 times higher than in the countries of the European Region [2].

The most probable and able-bodied part of the population have cardiovascular pathologies. The largest number of patients and deaths for this reason are among men aged 35-65. Experts of the Ministry of Health of the Republic of Kazakhstan note that the annual damage due to the CVD in Kazakhstan averages about 89 billion tenge [3].

The identification of a set of factors contributing to the development of atherosclerosis and CVD is one of the achievements of modern cardiology. The concept of risk factor appeared as a result of generalization of the data from large-scale prospective epidemiological researches. This conclusion is the base to prevent CVDs. Hypercholesterolemia, hypertension, and smoking belong to the main or «major» risk factors, the combination of these factors increases the risk of CVD by 3-10 times. There are a number of factors that make a little influence on the development of the CVD. These factors include gender, age of a person, hereditary predisposition to CVDs, physical activity, overweight, psychoemotional stress, and metabolic disorders [4]. 
Smoking, poor nutrition, overweight and obesity, low physical activity, dyslipidemia, hypertension, psychosocial, and diabetes belong to the leading modified risk factors for CVD. Risk factors for unmodified CVD include men over 45 and women over 55 years of age, male gender, coronary heart disease in relatives of the first degree of kinship, or family history of early occurrence of CVD (men - from 55 and women - from 65) [5].

One of the most significant and common risk factors for cardiovascular pathology is the arterial hypertension $(\mathrm{AH})$. The prevalence of this disease differs significantly in different countries: The incidence of the disease in the European population varies from $23 \%$ to $36 \%$, in the USA - $27-43 \%$ [6], and in India - 25.3\% (more often in men [27.4\%] than in 15 women [20.0\%]) [7]. Many researchers suppose that these indicators are slightly underestimated and taking into consideration the new recommendations of the American Heart Association/American College of Cardiology.

The favorable dynamics of the mortality of the population from CVD in our country appears with the realization of the Program for the development of cardiological and cardiac surgical aid in the Republic of Kazakhstan for 2007 - 2009, the State Program for the Development of Healthcare of the Republic of Kazakhstan «Salamatty Kazakhstan/Healthy Kazakhstan» for 2011-2015, the State Program for the Development of healthcare of the Republic of Kazakhstan «Densaulyk/Health» for 2016-2019, the State Program for the Development of Healthcare of the Republic of Kazakhstan for 2020-2025. These state programs provide for the modernization of the domestic healthcare system, including the development of the organizational structure of cardiological, interventional cardiological and cardiac surgical aid; the introduction of effective methods of prevention, early diagnosis, treatment and medical rehabilitation of patients and invalid people with CVD; training and advanced training of specialists in cardiac surgery profile, etc. [8].

The country has unequal distribution of health-care professionals on locality: As a rule, there is a higher density of health workers in urban areas because of better standards of living and higher salaries in comparison with rural areas. About $40 \%$ of the country population resides in rural areas and such patients have higher prevalence of chronic somatic disorders that need health-care interventions but travel burdens to specialty services may be unbearable for this population. Access to specialized care is a key priority in the managing of health administration and understanding the geographic distribution and province designation of this population in regard to medical centers can help in medical aid coordination. Moreover, absence of equal and fair access of the population to all levels of medical aid is also explained by poor road infrastructure [9]. Thus, the purpose of our research is to assess the general incidence of and mortality from CVD in urban and rural areas of the Republic of Kazakhstan in 2019.

\section{Materials and Methods}

\section{Research design and procedures}

This was a retrospective study on the basis of the data obtained from the statistical reports on the Republic of Kazakhstan «Health of the Republic of Kazakhstan and the activities of health-care organizations». This was a retrospective study on the basis of the data obtained from the statistical reports on the Republic of Kazakhstan «Health of the Republic of Kazakhstan and the activities of healthcare organizations». From this database, we got the information about CVD incidence and mortality in 2019.

Statistical reports on the Republic of Kazakhstan "Health of the Republic of Kazakhstan and the activities of health-care organizations" are published every year. This statistical book covers statistical materials on the activities of health-care organizations and health indicators of the population of the Republic of Kazakhstan and includes data about newly diagnosed cases of CVD and IHD that are collected by medical doctors who are working in primary health-care facilities all over the country. Data gathering process is standardized and obligatory for all primary practice medical doctors.

To enable comparative analysis of incidence and mortality rates, we divided the territory of Kazakhstan into five geographic areas: East that includes East Kazakhstan and Pavlodar provinces; West which covers Aktobe, Atyrau, Mangystau, and West Kazakhstan provinces; North that consists of Kostanay and North Kazakhstan provinces; South which covers Almaty, Zhambyl, Kyzylorda, and Turkistan provinces; and Central (Akmola and Karagandy provinces). In accordance with national policy, three cities - NurSultan, Almaty, and Shymkent are categorized as cities of republican subordination and are considered as provinces in statistical analysis.

\section{Ethical issues}

We did not use personal data for this reason as there was no need for information consent. Ethical committee of Semey Medical University (Semey, Kazakhstan) approved our research before it was started (Protocol 2 dated October 18, 2019).

\section{Statistical analysis}

Crude rates of incidence and mortality per 100,000 population were calculated. 
The total incidence rate was calculated as the ratio of the total number of diseases from CVDs to the estimated population:

- $\quad$ Number of new cases of CVD or IHD during one specified year in all age groups/midyear general population $\times 100,000$.

The crude mortality rate was calculated as the ratio between the total number of deaths because of CVD and estimated population number:

- Number of deaths from CVD during one specified year in all age groups/midyear general population $\times 100,000$.

All calculations were done with Statistical Package for the Social Sciences software, version 20.0 for Windows.

\section{Results}

Table 1 shows incidence of the population of the Republic of Kazakhstan which was registered in a healthcare organization in 2019. As it can be seen, incidence of CVD covers the main part of the general incidence (over $16 \%)$. In 2019, general incidence comprised 19,278,994 but CVD incidence was 3,144,167.

Table 1: Incidence of the population of the Republic of Kazakhstan registered in a healthcare organization

\begin{tabular}{llllll}
\hline Year & General incidence & & \multicolumn{2}{l}{ In particular CVD incidence } \\
\cline { 2 - 3 } \cline { 5 - 6 } & $\begin{array}{l}\text { Altogether } \\
\text { absolute numbers }\end{array}$ & $\begin{array}{l}\text { Per } 100,000 \\
\text { people population }\end{array}$ & $\begin{array}{l}\text { Altogether } \\
\text { absolute numbers }\end{array}$ & $\begin{array}{l}\text { Per } 100,000 \\
\text { population }\end{array}$ \\
\hline 2019 & $19,278,994$ & $104,133.8$ & $3,144,167$ & $16,982.9$ \\
\hline CVD: Cardiovascular disease. & & &
\end{tabular}

Table 2 presents the information about an issue of CVD in each areas of Kazakhstan in 2019. The chart shows each area of Kazakhstan with the information about how more people were ill and in general in rural areas of Kazakhstan, CVD was less than in urban areas.

Table 2: Incidence of CVD across provinces of urban and rural areas of Kazakhstan in 2019 (per 100,000 population)

\begin{tabular}{llll}
\hline Geographic zone & Province (City) & CVD & \\
\cline { 3 - 4 } & & Urban & Rural \\
\hline Republic of Kazakhstan & & 3068.4 & 2403.5 \\
East & East Kazakhstan & 3396.0 & 3452.8 \\
& Pavlodar & 3113.4 & 2737.9 \\
Central & Akmola & 3771.7 & 2505.0 \\
& Karaganda & 3111.3 & 1622.9 \\
North & Kostanay & 2249.1 & 2545.9 \\
& North Kazakhstan & 2328.9 & 2986.5 \\
\multirow{2}{*}{ West } & Aktobe & 1932.1 & 2521.7 \\
& Atyrau & 2255.3 & 2207.9 \\
& Mangystau & 3616.5 & 1232.5 \\
\multirow{5}{*}{ South } & West Kazakhstan & 1861.8 & 2823.5 \\
& Almaty & 3674.2 & 2319.7 \\
& Zhambyl & 3391.0 & 2746.5 \\
& Kyzylorda & 2932.9 & 2722.2 \\
Cities & Turkistan & 2372.9 & 2082.7 \\
& Nur-Sultan & 2843.5 & - \\
& Almaty & 3758.3 & - \\
\hline CVD: Cardiovascular disease. & Shymkent & 3418.6 & - \\
\hline
\end{tabular}

In East Kazakhstan, the number of disease in urban areas essentially equals with the number in rural areas. Differences between them are only 56 , but in central areas of Kazakhstan cities have more issues than rural areas. For instance, disease in Akmola is greater than in rural places in Akmola for 1266. It shows that countryside of central area is very healthy.

In addition, west sides of our Republic of Kazakhstan have very low result than in other sides. There are vice versa in chart, if in other areas of Kazakhstan, urban state is more than rural, but in West Kazakhstan, the parameter of disease in rural more than urban area, furthermore, it presents us that cities of west area are more healthy. The table shows the opposite, if in other regions of Kazakhstan, the urban state is larger than the rural one, but in West Kazakhstan, the incidence rate in rural areas is higher than in urban areas, in addition, it shows that the cities of the western region are healthier.

The next table (Table 3) presents the incidence of $\mathrm{AH}$ in cities and villages of Kazakhstan. In general, the incidence of $\mathrm{AH}$ of Kazakhstan in urban areas is slightly more than in rural areas, accordingly 1443.4 and $1227 / 100,000$ population. Looking at the details, the $\mathrm{AH}$ incidence in all urban regions is more than in rural regions, except East Kazakhstan, Kostanay, North Kazakhstan, and West Kazakhstan. The most incidence of $\mathrm{AH}$ was in urban population of Mangystau that was estimated 2227.4/100,000 population. However, the least incidence was in rural areas of Mangystau too (625.6/100,000 population).

Table 3: Incidence of $\mathrm{AH}$ across provinces of urban and rural areas of Kazakhstan in 2019 (per 100,000 population)

\begin{tabular}{llll}
\hline Geographic zone & Province & AH & \\
\cline { 3 - 4 } & & Urban & Rural \\
\hline Republic of Kazakhstan & & 1443.4 & 1227 \\
East & East Kazakhstan & 1510.2 & 1871.4 \\
& Pavlodar & 1263.1 & 1144.5 \\
Central & Akmola & 2623.8 & 1574.0 \\
& Karaganda & 951.8 & 835.8 \\
North & Kostanay & 1037.8 & 1197.5 \\
& North Kazakhstan & 630.5 & 1199.6 \\
West & Aktobe & 1009.2 & 734.9 \\
& Atyrau & 1396.5 & 1225.1 \\
& Mangystau & 2227.4 & 625.6 \\
South & West Kazakhstan & 1205.9 & 1607.6 \\
& Almaty & 1952.8 & 1259.5 \\
& Zhambyl & 1554.7 & 1414.7 \\
& Kyzylorda & 1406.5 & 1230.5 \\
Cities & Turkistan & 1410.0 & 1075.0 \\
& Nur-Sultan & 1212.2 & - \\
& Almaty & 1732.2 & - \\
\hline CVD: Cardiovascular disease, AH: Arterial hypertension. & 1733.9 & - \\
\hline
\end{tabular}

Table 4 demonstrates the incidence rates of IHD and acute myocardial infarction across different provinces of Kazakhstan in 2019. In common, it can be clearly observed that the incidence rates in cities are significantly higher than in villages. In this case, Almaty city had the highest indicator of IHD in 2019 that was equal to 850.8. The second highest rate was seen in the cities of Zhambyl province (792.4). In rural areas, the most incidence of IHD was observed in Zhambyl province. In addition, the lowest indicator of IHD was in Mangystau villages which were estimated 200.9. 
Table 4: Incidence of IHD and acute myocardial infarction across provinces of urban and rural areas of Kazakhstan in 2019 (per 100,000 population)

\begin{tabular}{|c|c|c|c|c|c|}
\hline \multirow[t]{2}{*}{ Geographic zone } & \multirow[t]{2}{*}{ Province } & \multicolumn{2}{|l|}{ IHD } & \multicolumn{2}{|c|}{ Acute myocardial infarction } \\
\hline & & Urban & Rural & Urban & Rural \\
\hline \multicolumn{2}{|c|}{ Republic of Kazakhstan } & 612.5 & 463.6 & 145.2 & 81.1 \\
\hline \multirow[t]{2}{*}{ East } & East Kazakhstan & 633.1 & 583.8 & 190.9 & 80.5 \\
\hline & Pavlodar & 585.6 & 599.3 & 134.7 & 122.5 \\
\hline \multirow[t]{2}{*}{ Central } & Akmola & 600.1 & 530.7 & 119.5 & 99.4 \\
\hline & Karaganda & 725.3 & 449.8 & 166.9 & 102.5 \\
\hline \multirow[t]{2}{*}{ North } & Kostanay & 408.8 & 416.2 & 112.5 & 78.0 \\
\hline & North Kazakhstan & 515.9 & 654.2 & 212.9 & 104.4 \\
\hline \multirow[t]{4}{*}{ West } & Aktobe & 431.9 & 393.4 & 178.4 & 15.3 \\
\hline & Atyrau & 330.1 & 287.9 & 114.6 & 148.3 \\
\hline & Mangystau & 542.6 & 200.9 & 175.7 & 36.9 \\
\hline & West Kazakhstan & 311.5 & 476.7 & 151.1 & 88.9 \\
\hline \multirow{4}{*}{ South } & Almaty & 713.5 & 457.3 & 141.0 & 78.9 \\
\hline & Zhambyl & 792.4 & 713.1 & 166.0 & 52.0 \\
\hline & Kyzylorda & 691.5 & 430.6 & 79.2 & 60.5 \\
\hline & Turkistan & 430.9 & 363.8 & 124.0 & 89.8 \\
\hline \multirow[t]{3}{*}{ Cities } & Nur-Sultan & 475.9 & - & 109.0 & - \\
\hline & Almaty & 850.8 & - & 133.4 & - \\
\hline & Shymkent & 554.4 & - & 166.1 & - \\
\hline
\end{tabular}

Another interesting point is that the highest number of acute myocardial infarction incidence was in urban areas of East Kazakhstan in 2019 (190.9). On the other hand, the lowest incidence rate of acute myocardial infarction was presented in rural population of Aktobe province, it comprised only 15.3. In contrast, the lowest acute myocardial infarction incidence number in urban regions was seen in Kyzylorda province (79.2). Detailed data on the incidence of IHD and acute myocardial infarction are demonstrated in Table 4.

The bar chart (Figure 1) illustrates the indicators of CVD incidence throughout the country in 2019. As can be seen from the chart, in rural areas, the incidence of CVD is less than in urban areas, accordingly 2403.5 and 3068.4. In particular, the incidence of $\mathrm{AH}$ takes half of CVD that was estimated 1227 and 1443 in rural and urban population accordingly. The incidence rates of IHD comprised 463.6 in rural regions and 612.5 - in urban region. Furthermore, the incidence rate in urban areas of acute myocardial infarction was almost 2 times higher than rural areas, 145.2 and 81.1, respectively.

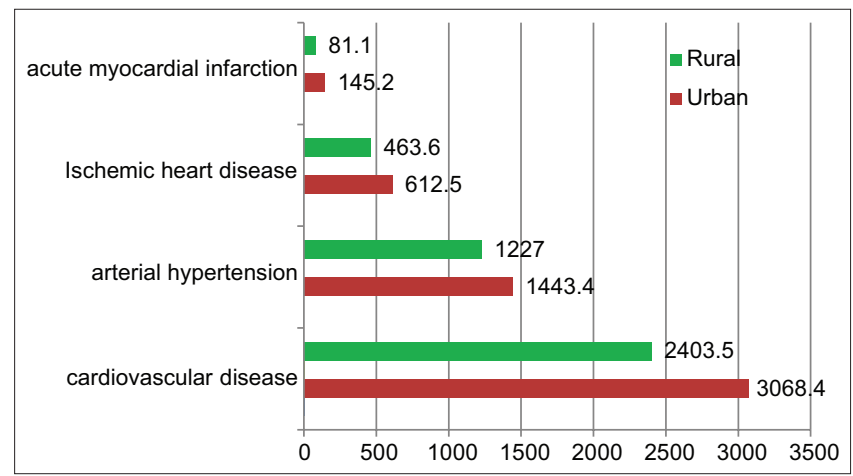

Figure 1: Incidence of cardiovascular disease in urban and rural areas of Kazakhstan in 2019 (per 100,000 population)

The map of Kazakhstan (Figure 2) presents mortality from CVD by provinces of Kazakhstan in 2019. Overall, the mortality rates from CVD in urban areas were higher in comparison with rural areas of Kazakhstan. The highest CVD mortality was observed in Karaganda province cities (365). East Kazakhstan

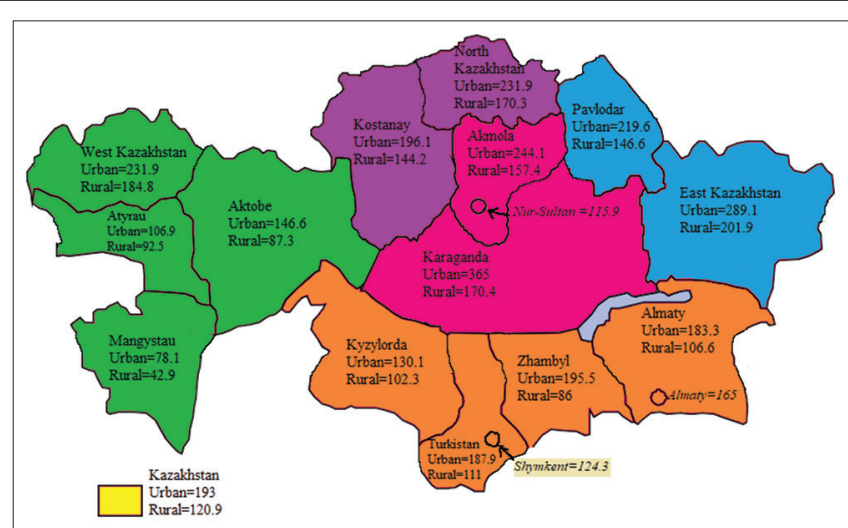

Figure 2: Mortality from cardiovascular disease in urban and rural areas of Kazakhstan in 2019 (per 100,000 population)

province cities had the second highest mortality rate of CVD in 2019 (289.1). In rural areas, East Kazakhstan (201.9) and West Kazakhstan (184.8) provinces had the highest rates that occupied first and second places among other provinces in 2019. The least mortality from CVD was in Mangystau province villages (42.9), also this province had the lowest rate among urban people (78.1). In general, in Kazakhstan, CVD mortality rate was 193 in urban and 120.9 in rural population.

Table 5 shows mortality rates from IHD in provinces of our country by urban and rural areas. In general, the mortality rates of cities are higher than villages across all provinces of Kazakhstan. East Kazakhstan had a peak of mortality in urban regions (135.4). Akmola, Karaganda, and North Kazakhstan provinces had the second, third, and fourth highest mortality rates following East Kazakhstan province. It can be clearly observed that the lowest mortality rate was shown in rural province, in particular in Mangystau province (8.5). Among urban population, the lowest mortality rate was seen in Atyrau province (24.1). Overall mortality from IHD in Kazakhstan was 71.4 and 38.7 in urban and rural areas, respectively.

\section{Discussion}

Thus, the results of this research demonstrate the incidence of CVD in urban areas higher than rural areas; it means that rural population of Kazakhstan is healthier than cities. This high number of CDV incidence has been observed in Eastern, Central, and Southern provinces of Kazakhstan, as well as in two large cities - Almaty and Shymkent. Still, a number of provinces of North Kazakhstan and West Kazakhstan (besides Mangystau) experienced low number of CVD incidence in cities. Although the least indicator of CVD incidence was in rural areas of Mangystau province per 100,000 population. As for the incidence of IHD, it was the same situation with incidence almost in all provinces of Kazakhstan during the research period. Actually, the 
Table 5: Mortality from IHD across provinces of urban and rural areas of Kazakhstan in 2019 (per 100,000 population)

\begin{tabular}{llll}
\hline Geographic zone & Province & IHD & \\
\cline { 3 - 4 } & & Urban & Rural \\
\hline Republic of Kazakhstan & East Kazakhstan & 13.4 & 38.7 \\
East & Pavlodar & 65.9 & 77.3 \\
& Akmola & 109.2 & 36.1 \\
Central & Karaganda & 111.8 & 71.8 \\
& Kostanay & 86.2 & 44.1 \\
North & North Kazakhstan & 96.9 & 58.6 \\
& Aktobe & 59.7 & 58.1 \\
West & Atyrau & 24.1 & 36.3 \\
& Mangystau & 29.6 & 27.0 \\
& West Kazakhstan & 79.8 & 8.5 \\
\multirow{4}{*}{ South } & Almaty & 57.6 & 65.0 \\
& Zhambyl & 79.6 & 35.5 \\
& Kyzylorda & 27.9 & 30.6 \\
\multirow{2}{*}{ Cities } & Turkistan & 32.3 & 27.2 \\
& Nur-Sultan & 44.6 & 24.5 \\
& Almaty & 80.8 & - \\
IHD: Ischemic heart disease. & Shymkent & 28.9 & - \\
& & & -
\end{tabular}

incidence of $\mathrm{AH}$ of cities was observed with the highest rates in Akmola and Mangystau provinces. However, the lowest data were in North Kazakhstan and Aktobe provinces. The incidence rate of acute myocardial infarction in urban areas was higher than the incidence in rural areas, especially East Kazakhstan, North Kazakhstan, Aktobe, and Mangystau provinces had the highest incidence rate. Mortality from CVD and in particular IHD of urban population is significantly higher than rural one. Urban provinces such as East Kazakhstan, North Kazakhstan, Akmola, and Kostanay had higher mortality rate than other provinces.

In 2014, the total mortality rate from CVD in Kazakhstan comprised 232.4/100,000 people; in 2015, it was $219 / 100,000$ people. In regional scale, the highest rate of CVD was registered in the Karaganda province with 368.1 deaths $/ 100,000$ in 2015 [10]. In rural areas, mortality rates were substantially lower than in urban areas. Among urban residents in 2014 , the total mortality rate from CVD comprised 238.3/100,000, while in rural areas, it was $162.2 / 100,000$. Kazakhstan ranks third in terms of mortality from IHD among the countries of the former Soviet Union [11].

Kazakhstan started realization of national health programs in 2011 and the first program launched was «Salamatty Kazakhstan/Healthy Kazakhstan», which was gradually transferred to the "Densaulyk/ Health» program scheduled for 2016-2020. CVD was among the greatest public health problems concerned by both programs. This helped to reduce the CVD mortality rate by $4.3 \%$. Within the implementation of the national health programs, clinical protocols were updated, legal regulatory documents were upgraded, medical facilities became better equipped, and more than 300 medical professionals got training abroad: In Israel, Russia, and Japan [12].

Kazakhstan is given to further reducing mortality from CVD and has developed a new regulatory document entitled "Human health and the healthcare system» and offered a new national public health program that is planned for 2020-2025. This program is based on cost-effective, evidence-based demographic strategies which are able to reach very broad segments of the population and includes legislative measures in order to control the use of tobacco products through taxation and restrictions on advertising. Other costeffective strategies are nicotine replacement therapy for refusal of smoking and therapy with a fixed combination of low doses to reduce blood pressure in patients with moderate or severe hypertension (25). The introduction of obligatory social health insurance system in Kazakhstan that will begin in 2020 will introduce solidary responsibility for the state of health. However, it is highly important that any such systems supply benefits for outpatient treatment and medicines and not only for hospitalization, which was the attention of earlier public health insurance schemes. Finally, improved health information systems such as a mortality surveillance system are necessary to inform about the policy in health sphere and set targets as well as to monitor the effects of intervention programs [13].

A national screening program for CVD and diabetes was introduced in Kazakhstan within the period from 2011 to 2015. Screening of CVD in Kazakhstan is performed every 2 years as a part of free medical care in all district polyclinics for men and women aged $18,25,30,35$, and $40-64$ years who have not been diagnosed with heart disease or diabetes. In the course of the screening, they give patients a questionnaire that evaluates risk factors and they measure their height, weight, blood pressure, cholesterol, and blood sugar levels [14]. Individuals with high risk of cardiovascular mortality got referrals to have further treatment. From 2011 to 2015, more than 7.5 million adults in Kazakhstan were screened for the presence of CVD. As a result, more than 600,000 cases of heart disease were revealed $(7.9 \%$ of the number screened) [15].

It is considered that residents of rural regions comprise $40 \%$ of the population of the Republic of Kazakhstan. A major proportion of the rural population lives under the conditions of undeveloped transport communications and the lack of modern means of communication that broadly explains the low level of their appeal to health-care centers. Rural residents' appeal to health-care centers is 2.5 times lower than that of urban residents. It is necessary to notice the prevalence of chronic non-contagious diseases among the rural population (chronic diseases of the circulatory systems, respiratory organs, blood diseases, and diabetes mellitus) that take a leading place in the structure of mortality, disability, and morbidity in all countries of the world [16].

$\mathrm{AH}$ is one of the most widespread diseases in Kazakhstan and constitutes a serious problem for public health. In the period from 2009 to 2013 , the prevalence of AH increased essentially from 10,778 to $13,392 / 100,000$ people, as a result of what $24.3 \%$ of Kazakhstan adult population suffered from hypertension in 2013 [17]. The rates of mortality connected with hypertension have also increased and currently take the first place among 
the causes of death. About $40 \%$ of deaths were noted in the able-bodied age group (20-64 years), 64\% of which were men. To restrain this epidemic, the State Health System has created a screening program for early revealing of CVD and factors of their risk [18]. Majority of the patients examined through screening had not earlier got any treatment for their health conditions [19]. In our research, as well as in researches carried out in Asian and European countries, it was shown that the prevalence of hypertension is higher among urban residents [20]. However, in spite of the lower prevalence of $\mathrm{AH}$, rural residents with $\mathrm{AH}$ often remain without screening and the severity of the disease and its complications are substantially higher. At the younger ages of 18 and $39, \mathrm{AH}$ is diagnosed less often in rural population than in urban ones $(p<0.05)$. Rural respondents, as a rule, go to polyclinics only when they have serious health problems. In this group, the disease is more often diagnosed at a later age and at later stages of development that brings to increased health risks and extra expenses for the patient and the health-care system [21].

The education level varied between communities and share of people with higher formal education was lower in rural areas than in cities and towns. There are strong links that have been documented in many researches between socioeconomic variables (education, profession, income, and marital status) and the development of CVD in the countries with different socioeconomic status, as well as among rural or working age populations. Only a few studies have explored this issue in countries with an economy in transition like former Soviet Union countries, such as Kazakhstan [22].

Advantage of our research is we used official statistics as our data, and thus, the quality of our results depends on the quality of the reporting documentation. The limitation of our research is our dependence on the reporting format adopted in the Republic of Kazakhstan that makes it impossible to compare the data with the results of most foreign and Russian researched. However, these limitations cannot reduce the consequences of the fact that this is the first study to assess the inequality of morbidity and mortality from CVD between urban and rural areas of Kazakhstan.

\section{Conclusions}

Rural-urban health disparities exist in many countries and CVD is not the exception. Although an ample body of international research reports on poorer outcomes for rural population, this was not a matter of fact for Kazakhstan, where rural population tends to have both lower incidence and mortality rates. It might be due to worse access to health-care facilities, typical for rural areas of Kazakhstan, and lack of modern diagnostic equipment, which can prevent from timely diagnosis. Thus, there is a need for prospective cohort studies to ascertain and explain this phenomenon. Besides, urban population of Kazakhstan might benefit from tailoring of preventive strategies targeted on cardiovascular risks reduction.

\section{References}

1. World Health Organization. Health Topics Cardiovascular Diseases. Cardiovascular Diseases. Geneva; World Health Organization; 2019. Available from: https://www.who.int/healthtopics/cardiovascular-diseases/\#tab=tab_1. [Last accessed on 2021 Jul 21].

2. Sultanbekov RT, Isabekova AH, Musagalieva AT. Achievements and problems of the cardiology service of the Almaty region. Ther Bull 2012;7:56-63.

3. Kozhekenova LG. Peculiarities of the organization of cardiological care for acute myocardial infarction in the Republic of Kazakhstan and abroad. Sci Healthc 2014;5:12-8.

4. Alexandrov AA. Recommendations for the prevention of cardiovascular diseases in childhood and adolescence. Russian J Cardiol. 2012;6:1-39.

5. Lynch EB, Liu K, Kiefe Cl. Philip Greenland cardiovascular disease risk factor in young adults and 10-year change in risk factors: The coronary artery risk development in young adults (CARDIA) study. Am J Epidemiol 2006;164:1171-9. http://doi. org/10.1093/aje/kwj334

PMid: 17038418

6. Kim EJ, Kressin NJ, Paasche-Orlow MK, Lopez L, Rosen JE, Lin $\mathrm{M}$, et al. Racial/ethnic disparities among Asian Americans in inpatient acute myocardial infarction mortality in the United States. BMC Health Serv Res 2018;18:370. http://doi. org/10.1186/s12913-018-3180-0

PMid:29769083

7. Gupta R, Gaur K, Ram CV. Emerging trends in hypertension epidemiology in India. J Hum Hypertens 2019;33:575-87.

8. Kamaliev MA, Alimbaeva SH. Organizational and methodological approaches to the rational management of the process of reducing mortality from diseases of the circulatory system. Bull KazNMU 2021;2:79-82.

9. Gawron LM, Pettey WB, Redd AM, Suo Y, Gundlapalli AV. Distance to veterans administration medical centers as a barrier to specialty care for homeless women veterans. Stud Health Technol Inform. 2017;238:112-5.

PMid:28679900

10. Ministry of Health of the Republic of Kazakhstan. Health of the Population of the Republic of Kazakhstan and the Activities of Health Organizations in 2014. Ministry of Health of the Republic of Kazakhstan; 2015.

11. Aringazina A. Development and Sustainability: The Challenge of Social Change. London: ZED Books Ltd.; 2016.

12. Program of the Meeting Board of the Ministry of Health of the Republic of Kazakhstan. Available from: http://www.rcrz.kz/files/ kollegii/aktayevspresentationonmeasurestoreducemortality.pdf. [Last accessed on 2020 Oct 27].

13. Drafts of the Law Regulatory Document "People's Health and the Health Care System" and the State Program for Improving Public Health for 2020-2025; 2019. Available from: http://www. rcrz.kz/images/Presentation_public_050619.pdf [Last accessed 
on 2019 Nov 21].

14. Health of the Population of the Republic of Kazakhstan and the Activities of Health Organizations in 2014. Ministry of Health of the Republic of Kazakhstan; 2015.

15. Health of Population and Health Care in the Republic of Kazakhstan in 2013; 2013. http://www.medinfo.kz [Last accessed on 2018 Jun 11].

16. Nogaeva MG, Tuleutayeva SA. Prevalence of cardiovascular disease in Kazakhstan. J Med. 2014;10:13-6.

17. State Program on Health Systems" Development for the years 2011-2015. Ministry of Health of the Republic of Kazakhstan; 2010.

18. Order of the Ministry of Health \#145. Ministry of Health of the Republic of Kazakhstan; 2011.

19. Basic Indicators of Population Health and Activity of Health
Organizations of the Republic of Kazakhstan from 2000 to the Present. Available from: http://www.medinfo.kz/\#/dpsraion [Last accessed on 2018 Jun 11].

20. Walter WH, Susie S, Cristina M. Bases of Policy. Screening in Europe. WHO on Behalf of European Observatory on Health Systems and Policy. Vol. 76. Geneva: World Health Organization; 2008. p. 16-59.

21. Shinbolatova A, Kulzhanov M, Aringazina A, Nurbakhyt A. Screening of arterial hypertension in the republic of Kazakhstan: Advantages, disadvantages and ways of improving. Iran $\mathrm{J}$ Public Health. 2014;43(12):1695-701.

PMid:26171363

22. Yiqui L, Wright SC. Knowledge and awareness of risk factors for cardiovascular disease in the Ga-Rankuwa community. Health SA Gesondheid 2008;13:31-41. 